\title{
Understanding the Social Science Effect: An Intervention in Life-Course Generosity
}

\author{
Patricia Snell Herzog, Lilly Family School of Philanthropy, IUPUI ${ }^{1}$ \\ Casey T. Harris, Sociology \& Criminology, University of Arkansas \\ Shauna A. Morimoto, Sociology \& Criminology, University of Arkansas \\ Jared L. Peifer, Narendra Paul Loomba Department of Management, Baruch College
}

\begin{abstract}
Does interacting with social science data in early adulthood promote generosity? To investigate this question from a life course development perspective, two distinct samples were drawn for a survey with an embedded experimental design. The first sample is of emerging adult college students $(\mathrm{n}=30$, median age $=20$ years). The second sample is of young adults who were selected to participate based on their prior participation in a nationally representative and longitudinal study $(\mathrm{n}=170$, median age $=31$ years $)$. Toward the end of the survey, participants were randomly selected into a website interaction with either: (a) data on charitable giving, (b) data on social inequality, or (c) data about weather (a control condition). The key outcome of interest is a behavioral measure of generosity: whether participants elected to keep their study incentive or donate their incentive to a charitable organization. The donation decision occurred after the randomly selected website interaction. Interacting with charitable giving data resulted in greater generosity than interacting with weather data, across both samples. Interacting with social inequality data had mixed results. Moreover, emerging adult college students gave at a considerably higher rate overall than the national sample of young adults, net of treatment type. Implications are discussed.
\end{abstract}

Keywords: generosity, charitable giving, emerging adulthood, life-course development

This paper is accepted for publication in the American Behavioral Scientist, within a 2019 special issue entitled, "The Science and Imagination of Living Generously."

\footnotetext{
${ }^{1}$ Corresponding author: Patricia Snell Herzog, PhD, Melvin Simon Chair and Associate Professor of Philanthropic Studies in the Lilly School of Philanthropy at IUPUI, 301 University Blvd., Indianapolis, IN 46202. Email: psherzog@iupui.edu. Acknowledgments: The authors would like to thank several graduate and undergraduate students for their contributions to this project, including Christina Williams, De'Andre T. Beadle, Tasmiah Amreen, Tiffany E. Hood, Bryn Smernoff, Sanjana Venugopal, Tatianna Balis, and Emma Turner. The authors are also grateful for the generous funding of this project by the Lilly Family School of Philanthropy at IUPUI.
} 


\section{Understanding the Social Science Effect: An Intervention in Life-Course Generosity}

The original goal of American sociology was to improve society by lessening, even eradicating, social problems (Turner \& Turner, 1990). However, the quest to establish itself as a form of science led to a distancing over time of sociology from its ameliorative roots (Addams, 1999). The rise of scientific logic promoted a norm in mainstream American sociology of reporting results as descriptive and unbiased, deemphasizing their implications for moral action (Deegan, 1988), which has led some to critique sociology as being too abstracted from its subject matter and losing relevance in helping society (Vaughan, Sjoberg, \& Reynolds, 1993). Thus, in this article, we return to the ameliorative roots of sociology to reimagine the ways that social science may contribute to a social good: greater generosity.

The purpose of this study is to ascertain whether interacting with two distinct types of social science data during early adulthood promotes generosity. To investigate this, we employ an experimental design to examine if individual decisions about generosity — namely, the choice to keep or give one's study incentive - vary in response to a social stimulus. In particular, we are interested in whether interacting with social science data causes increases in the rate of giving, effectively indicating that social science data contributes to producing a social good. Sociology often begins with the assumption that people are socially patterned agents who make decisions based on information about their broader social context. However, to our knowledge, there are no studies that directly test this, and we offer a first examination of this assumption. Moreover, we are interested in what types of social science data may affect decisions about giving, and therefore, we investigate a comparison between social science data about charitable giving, as compared with social science data about social inequality. We compare both of these 
interventions to interactions with non-social-science data, which serves as our experimental control condition.

\section{Literature Review}

\section{Social Science \& Prosociality}

First, we review existing literature on these topics, beginning with why we attend to prosocial behaviors. Prosocial behaviors have a long history of being studied in social science, and many of these studies draw on classical social theorists, such as Émile Durkheim and Max Weber (e.g., Christensen, Rothgerber, Wood, \& Matz, 2004; Paluck \& Shepherd, 2012; Zou, Tam, Morris, Lee, \& Lau, 2009). Continuing in this vein, we advance this tradition by examining a key prosocial behavior: charitable giving.

A common theoretical approach to understanding prosocial decisions is that people are generally rational actors, who conduct cost-benefit analyses in deciding on efficacious actions (e.g., Scott, 2000). From this perspective, individuals are inclined to make the decision that returns the best personal reward for the least personal cost. Moreover, people are also logical actors who compute a wide array of sensory experiences to comprehend the best actions (Bandura, 1989). Thus, individuals process social stimuli and economic outputs to make personal decisions. From this individual-focused perspective, people act prosocially when doing so is not too costly. For example, individuals may be more inclined to donate money when they have more money from which to give, since the personal cost of their donation is perceived to be low.

Drawing on this theoretical perspective, we sought to minimize the personal cost of donating by offering participants in our study a monetary incentive (\$50), as a token of appreciation for their time. We then asked participants whether they wanted to keep this 
incentive or donate it to a charitable organization. Extant studies find that giving is correlated with survey results showing high levels of altruism (Carpenter, Connolly, \& Myers, 2008), and thus we consider the decision to keep the incentive as demonstrating a self-motivated action: rewarding self, whereas electing to donate the incentive instead reflects a prosocial behavior: rewarding others.

However, individual-level factors, such as personal cost-benefit analysis, are not sufficient in explaining prosocial motivations. People are not isolated individuals who make decisions in a social vacuum. Rather, people are in constant interaction with their social contexts and are, thus, in the process shaped by social forces (Elder, 1994; Pescosolido, 1992). Personal decisions are made within differing structural conditions, such as relatively higher or lower socioeconomic status positions (J. R. Blau \& Blau 1982). Thus, people act in ways that reflect a combination of their personal self-interests, in conjunction with their positions within their broader social context. From this social-focused perspective, people are more inclined to act prosocially when social contextual cues indicate that prosocial behavior is needed. Thus, even a person with modest discretionary funds may act prosocially, incurring higher personal costs than a more affluent person, when they perceive this to be necessary. Generosity is not only about personal gain from cost-benefit analysis but also about altruistic social impact.

We theorize that social science data provide cues about the social context and thus can alter individual decisions to act prosocially. At the broadest level then, we investigate in this article the following research question: Does interacting with social science data promote prosocial behavior, specifically charitable giving? Yet, we do not end with this question alone, as we are curious to know whether the content of the social science data presented impacts giving rates. Specifically, we examine the effects on giving of interacting with social science 
data that presents information about: (a) social inequality (i.e., establishing a need) and (b) charitable giving normative patterns (i.e., showing giving rates). To explain why these two social science data interactions, and to identify distinctions in their social change mechanisms (if the data affect giving), we next review theories regarding what kind of social cues may impact behavior by focusing on two theories: social norms and social needs.

\section{Social Norms or Social Needs}

Different theoretical traditions identify distinct mechanisms explaining why people respond to social cues. We are interested in probing social theories further by investigating which social theories are most applicable in explaining responses to social science data. The two theoretical frameworks of interest are those stemming from Max Weber (1904/1946, 1913-1917/1949; and Émile Durkheim (1919/1982). For the purposes of this article, we conceive of these frameworks as undergirding two distinct theoretical expectations, which we pose here as alternative hypotheses regarding which social forces impact giving to charitable causes. Both posit a social response, but each posits different mechanisms: social norms or social needs.

Social Norms. Durkheim (1919/1982; 1893/1984) viewed people as mostly "internalizers" of the external social norms and customs of their national and group contexts. If people respond to social science data, Durkheim would presume it is because those data detail what is normative, clarifying social facts regarding the expected actions among their reference group. From this approach, altruism is theorized to be functional for society, and thus it would be considered deviant to not act altruistically. People are therefore compelled to give out of a sense of social solidarity and responsibility. For example, individuals are more likely to act prosocially when they are made aware of normative expectations to give. Thus, 
seeing a high rate of charitable giving by others may influence one to give. People desire to fit in, and data could show that charitable giving is a socially acceptable form of expected prosocial behavior.

Connecting this with contemporary studies of prosocial behaviors, the assumption is that people are compelled to give to charitable causes because this fulfills the normative expectation that it is good to act on behalf of the well-being of others (DellaVigna, List, \& Malmendier, 2012; Frey \& Meier, 2004). For example, Raihani and McAuliffe (2014) and McAuliffe, Raihani, and Dunham (2017) find that adults and children, respectively, are responsive to normative data about giving. In the latter study, older children-9-year-olds, as compared with 4-year-olds-were more likely to give when exposed to social norms that showed giving behavior to be typical and expected. In this study by McAuliffe et al. (2017), the descriptive information alone regarding the relative presence of giving behavior was equally effective as injunctive norms that told children that giving was expected. In other words, merely seeing data about the charitable giving of others encouraged children to give. Thus, from this theoretical and empirical lineage, we derive a social norm expectation, such that individuals will be more likely to donate when exposed to information about others' giving.

However, there may be impediments to the effectiveness of a social norm mechanism. For example, people could assume their situation is different from the average, and therefore view general norms as not applying. Perhaps people consider others to be better equipped to give: presuming others make more money, have more education, are older, and so on. In other words, people may respond only to the groups with whom they identify for social norm information (Abrams \& Hogg, 1988; Hogg \& Reid, 2006). These identity perceptions could 
theoretically undercut a general social norm mechanism, since people could view a norm as applying only to those who are considered to be better equipped to give (i.e., groups with whom they do not identify). To account for this, our study will provide average giving rates of people in the same general social identity categories as the study participant, in terms of income level, age, and educational attainment. We thus expect that people who are exposed to aver- age charitable giving trends that are tailored to their social segment, will give more in order to fulfill societal expectations of prosociality. More formally, our first hypothesis states, Hypothesis 1: People are more likely to give after interacting with social science data that report charitable giving norms for similar people (i.e., visualizations of charitable giving rates and amounts for people within the same social segment as the participant).

Social Needs. As an alternative to the Durkheimian perspective above, Weber (1904/1946, 1913-1917/1949) viewed society as the source of meaning for individual actors, whose socially derived interests and values guide their actions. If people respond to social science data, Weber would presume it is because those data are meaningful and interact with their cultural values to motivate a response. Applying this theoretical framework to charitable giving, one assumption would be that people are compelled to give to charitable causes when confronted with information that threatens their values.

For example, one widespread cultural value in the United States is distributive jus- tice: valuing an equitable distribution of resources, and confrontation with unequal distributions can compel desires for more socially just redistribution of resources (Hochschild, 1981). Connecting this with contemporary studies, researchers find that viewing unjust social conditions compels prosocial actions (Bekkers \& Wiepking, 2011). Additionally, differences in generosity by income were lessened by the degree of inequality described to study 
participants (Côté, House, \& Willer, 2015). Moreover, it appears that generous responses to unequal stimuli may increase with age, as a study comparing children from seven different national and cultural contexts found that older children (5-year-olds) are more generous than younger children (3-year-olds; Rochat et al., 2009). Plus, individuals are more likely to act prosocially when they are made aware of the social needs that could be addressed through their actions (Bekkers \& Wiepking, 2011; Derin-Gure \& Uler, 2010). Thus, from this theoretical and empiri- cal lineage, we derive a social needs expectation, such that individuals would be more likely to donate when they are exposed to information that challenges the value of distributive justice. Namely, viewing data that highlights the existence of social inequality will compel an ameliorative response to give.

We test this theory in our study by exposing individuals to visual representations of the unequal distribution of income based on social characteristics, such as race and ethnicity, gender, and marital status. As such, a Weberian social need mechanism pos- its that people are compelled to act on their values by responding to lessen (or even eradicate) an unjust social situation, such as social inequality. The visual displays data that threatens the notion that income is equally distributed across diverse segments of the population. Instead, the data evidence a high correlation between economic status and social status. For example, married couples have greater income on average than single individuals, and higher income levels are more heavily populated by White individuals than are lower income levels. In essence, these data challenge the value of distributive justice by showing that economic goods are distributed based on caste-like social characteristics, such as race. We expect that interacting with these data will compel people to give out of a redistribution value and test the effect of these social need data. More formally, our second hypothesis states, 
Hypothesis 2: People are more likely to give after interacting with social science data that visualize social stratification, namely data that show an unequal distribution of income and facilitates participants in placing their income and social statuses within this distribution.

In summary, we expect people to be responsive to social science data. We test the effects on giving of interacting with two distinct forms of data, allowing for a compari- son between the two treatment groups that are exposed to these different data sets. In the first treatment group, we are interested in testing a social norms mechanism by investigating the impact of interacting with website data presenting charitable giving trends for average Americans, with data segmented to shared social characteristics of the respondents. In the second treatment group, we are interested in testing a social needs mechanism by investigating the impact of interacting with website data present- ing social inequality trends for average Americans, with data similarly segmented to shared social characteristics of the respondents. Thus, we investigate two different questions in one experimental design: (a) Does interacting with social norm data influ- ence propensity to give? and (b) Does interacting with social inequality data influence propensity to give? If one of the treatment groups gives more than the other treatment group, we can adjudicate between the effectiveness of different response mechanisms: social norms versus social needs.

\section{The Life Course and Prosocial Behavior}

Additionally, we are interested in the application of life course development theory and consider whether study results differ across participant samples that vary by age and life stage. Specifically, we compare results of a college sample of emerging adults (median age $=$ 20 years) with results of a national sample of young adults (median age $=31$ years). 
In terms of campus-based samples, prior studies indicate that there is a "giving type" among college students (Benz \& Meier, 2008; Laury \& Taylor, 2008; see also de Oliveira, Croson, \& Eckel, 2011). For example, Benz and Meier (2008) show that students who give to a charity are also more likely to contribute to the university funds. Other results regarding student giving show mixed outcomes, with Laury and Taylor (2008) showing correlation between giving behavior in college students in the lab and giving to an independent charitable organization. In summary, voluntary college-based samples may include people with a greater propensity to give, since volunteering to participate in a study itself can be thought of as a prosocial behavior.

\section{Experimental Design}

Many charitable giving studies rely on data collected from surveys that invite respondents to self-report their charitable giving. These self-reported measures of charitable giving, however, are often inaccurate. People can inaccurately report because of miscalculations of total household contributions, or people can over-report due to social desirability bias (Bekkers \& Wiepking, 2010). For instance, by comparing self-reported giving to a specific charity with that charity's records of receipt, Bekkers and Wiepking (2010) find that respondents overestimated their contributions by 30.5 percent. Wilhelm (2016) also finds different survey methodologies tend to generate disparate charitable giving estimates.

Careful study designs can ameliorate the inaccuracy of self-reporting by measuring actual behaviors with real money, often in field experiments or laboratory games (Vesterlund, 2016). We take a similar behavioral approach in this study, by offering study participants the opportunity to donate their $\$ 50$ survey incentive to a charitable organization or, alternatively, to keep the incentive for themselves. 
However, Carpenter and colleagues (Carpenter, Burks, \& Verhoogen, 2005; Carpenter et al., 2008) find that, when experimentally compared, community members are more likely to give than college students, even if the students are more affluent than those in the community sample. Moreover, for independent nonstudent samples, Eckel and Grossman (1996) find that giving to a charity is significantly higher than donations to an anonymous individual. Thus, noncollege campus samples from the general population may give at a higher rate than college students, especially when asked to donate to a charitable organization rather than an individual.

At the same time, recent literature examining the behavior of young people shows a steady uptick in volunteerism, service, and other types of prosocial behavior (Porterfield \& Winkler, 2007; Putnam, Frederick, \& Snellman, 2012). Indeed, contemporary college students indicate high levels of altruism and find contributing to their communities as more personally meaningful than earning a higher salary (Arnett, 2015). Thus, the expectations are mixed regarding whether college-based samples will have higher or lower giving rates than samples drawn from the general public. Weare thus interested in comparing results from a typical campus-based sample with results from a national sample. Our samples also differ in terms of age and life stage: the campus-based sample includes emerging adults who are 18 to 22 years old, and the national sample includes young adults who are 28 to 34 years old, who also differ in terms of educational attainment.

In summary, our samples allow for a comparison across age and life stage, combined. Few studies examine this comparison, and the few existing studies have mixed results. Thus, we are not able to draw theoretically informed expectations regarding how the results are hypothesized to vary between the two groups. Instead, the two-sample component of the study 
is considered exploratory in nature and can contribute new theoretical expectations and foster greater attention to age and life stage in future studies. We therefore compare the overall rate of giving across the two samples (between-samples), as well as compare the experimental results associated with each website interaction between the two samples (between-groups, between-samples).

\section{Data and Methodology}

\section{Experimental Design}

To test our hypotheses, we conduct a one-by-three, between-subject, experiment embedded within a survey. Participants answer a series of survey questions (e.g., questions on gender, race-ethnicity, parental educational attainment, employment status, occupation, and questions regarding transitioning into adulthood and leadership identity). After completing typical survey questions, participants then enter the experimental design and are randomly assigned, within the survey, to one of three groups - a control group, a social norms condition, or a social needs condition. Participants in each condition are instructed to interact with a website. The control group interacts with a weather website and participants are instructed to input their zip code, in order to view weather conditions in their local area. This is considered a benign website interaction that contained no social science data and provides a baseline for donation proclivity without any social science data intervention.

In the social norms condition (referred to below as the "giving treatment"), participants are instructed to visit a website with interactive charitable giving data. The website, GenerosityForLife.org, asks visitors to enter their basic demographic information and their 
giving behavior (see top of Figure 1). ${ }^{2}$ Subsequently, the interactive website displays average charitable giving data for people in the U.S. who share the demographics of the participant (see bottom of Figure 1). A survey question then asks participants to computer their own giving and then report: "What percentage of households like yours gave more than you?" and "What is the average annual household giving by people like you?" Third, the last question of this section asks participants to scroll to the bottom of that same web page to see the map of the U.S. and then select a response to: "What region has the highest median amount of money given by people like you - Northeast, South, North Central, or West?"

\section{[Insert Figure 1 About Here]}

In the social needs condition group (referred to below as the "inequality treatment"), participants visit a website with interactive social stratification data. The website contains visuals created by Stephen Rose (2015, New Press and entitled, Social Stratification in the United States, which displays aggregated U.S. Census data. Viewers enter their basic demographic information (see top of Figure 2) ${ }^{3}$. Then they are asked to find the income bracket representing their annual household income and find the icon within the bracket that best combines their household demographic statuses (see bottom of Figure 2). For example, the brackets represented in Figure 2 include $\$ 60,000-\$ 125,000$ annual household income on the left side, as compared to the considerably smaller number of households displayed in the right side for $\$ 150,000-\$ 400,000$ annual household incomes. Subsequently, the survey asks participants: "How do you think your family ranks relative to the average American? Significantly below, somewhat below, average,

\footnotetext{
2 At the time of this data collection, the GenerosityForLife.org website was under construction. Participants viewed a wireframe version of the Give-O-Meter tool which is now publicly available on the website. The images now available are slightly different from the images displayed to participants, which are reprinted in Figure 1 with permission of the IU Lilly Family School of Philanthropy and the Polis Center at IUPUI.

3 Figure 2 displays an excerpt from Social Stratification in the United States: The American Profile Poster Copyright $(02014$ by Stephen J. Rose and Carol Higgs. Reprinted by permission of The New Press. www.thenewpress.com
} 
somewhat above, or significantly above average." Thus, participants interact their individual data with the overall American social stratification distribution to gain a sense of the inequitable distribution of income across combinations of social statuses.

[Insert Figure 2 About Here]

\section{Samples}

We conduct the same experiment with two different samples. First, the study leverages data from a college sample, which we used, in part, to test the design procedures, and which we also compared to the second sample. In the second sample, we draw upon data from the same experimental design administered to a larger, national sample of young adults.

College Sample (Sample 1). For our first sample, we recruited students from a large, public university in the middle U.S. The call to participate was distributed widely across campus, without selecting any particular respondents into the sample, as is common in many campusbased samples. Fifty-five students responded to the call and participated in the study during the spring of 2016. Of these students, forty-two participants answered the survey demographic questions. As is statistically probable at most U.S. large, public universities, especially in the middle of the U.S., the sample is predominantly white $(76.19$ percent white, $n=32 ; 2.38$ percent black, $n=1 ; 2.38$ percent Latino, $n=1 ; 9.52$ percent Asian, $n=4 ; 9.52$ percent multiracial, $n=4$ ). Since this racial and ethnic demography is typical of the majority of the United States, we view this as contributing a typical middle U.S. public university sample to the literature, which is often populated by studies based upon the atypical racial and ethnic demography of universities within large metropolitan areas on the east and west coasts. The campus sample has more females than males ( 74.55 percent female, $n=41 ; 25.45$ percent male, $n=14)$. To some extent this mirrors the gender distribution of the broader university as being more female (53 percent) than male (47 
percent), but study participants were skewed more female. The median age for this sample is 20 years old and the participants were mostly from middle class household income levels (20.00 percent from $\$ 0-\$ 25,000, n=8 ; 7.50$ percent from $\$ 25,001-\$ 50,000, n=3 ; 20.00$ percent from $\$ 50,001-\$ 100,000, n=8 ; 32.50$ percent from $\$ 100,001-\$ 150,000, n=13 ; 20.00$ percent from $\$ 150,001-\$ 350,000, n=8 ; 0.00$ percent from More than $\$ 350,000, n=0)$. A total of thirty participants completed the survey in full and thus participated in the giving experiment $(\mathrm{n}=30$, 54.45 percent completion rate).

National Sample of Young Adults (Sample 2). The second sample was drawn from the longitudinal and nationally representative sample of the National Study of Youth and Religion (NSYR, e.g., Smith \& Snell 2009). We selected the 300 participants from the former NSYR participants who were interviewed at any time during their decade-long participation in the NSYR, i.e. all the interviewees of that study. These former NSYR participants had largely completed college by the time of the last NSYR survey (3.90 percent no degree, 43.97 percent high school or GED, 9.22 percent associate's or vocational degree, 37.23 percent bachelor's degree, and 5.67 graduate or professional degree.) We received a high response rate from the former NSYR interviewees: 182 participants began the survey (60.67 percent response rate), and 180 participants responded to the survey demographic questions (98.90 completion rate). The survey was conducted in the fall of 2016. Compared to our first sample, the participants were older (median age=31), working (66.51 percent working full-time, 15.09 percent working parttime, 18.4 percent not working), and mostly not enrolled in college (84.92 not enrolled in school, 13.41 percent enrolled, and 1.68 percent describing their enrollment status as complicated). The national sample was more gender-balanced (55.00 percent female, $n=99 ; 45.00$ percent male, $\mathrm{n}=81$ ). The participants also represented greater racial diversity ( 74.44 percent white, $\mathrm{n}=134$; 
8.89 percent black, $\mathrm{n}=16 ; 7.78$ percent Latino, $\mathrm{n}=14 ; 3.33$ percent Asian, $\mathrm{n}=6 ; 5.56$ percent multiracial, $\mathrm{n}=10)$, and spanned a greater distribution across household income levels (10.56 percent from $\$ 0-\$ 25 K, n=19 ; 28.89$ percent from $\$ 25 K-\$ 50 K, n=52 ; 37.78$ percent from $\$ 50 \mathrm{~K}$ $\$ 100 K, n=68 ; 13.89$ percent from $\$ 100 K-\$ 150 K, n=25 ; 6.11$ percent from $\$ 150 K-\$ 350 K, n=11$; 2.78 percent from $\$ 350 \mathrm{~K}$ plus, $n=5$ ). A total of 170 participants completed the survey in full and thus participated in the giving experiment $(n=170,93.40$ experiment completion rate and 56.67 percent overall response rate).

\section{Measures}

Outcome Measure. Whether or not respondents elect to keep or donate their study incentive provides the dichotomous outcome measure for this study. By providing the respondents with this incentive money, in this field experiment design, we are able to focus on the giving decisions that people make when they have the perception that they have money in hand to give. This essentially holds constant whether respondents perceive themselves as having the money available and focuses instead on the willingness to donate available money. We then test how willingness to donate available money is affected by website interactions. Prior to making give-or-keep decisions, study participants were randomly selected into one of the three website interactions described above. In the results that follow, these assignments are referred to as: control group, social norms group, or social needs group.

Covariates. Alongside the assigned experimental group, the following measures are included as covariates in the forthcoming models: (1) gender (Which of these best describes your gender? $0=$ Male, $1=$ Female); (2) race and ethnicity (Which racial or ethnic category best describes you? White, Non-Hispanic, Black, Non-Hispanic, Latino or Hispanic, Asian or Pacific Islander, Native American, Multiracial (two or more races or ethnicities), Other, or It's 
Complicated, with explanation specification. Due to the small cell sizes within each of these more specific racial and ethnic categories, we combined responses into a binary variable: $0=$ White, $1=$ non-White); and (3) an ordinal measure of income with the following income categories $(\$ 0-\$ 25,000 ; \$ 25,001-\$ 50,000 ; \$ 50,001-\$ 100,000 ; \$ 100,001-\$ 150,000 ; \$ 150,001$ $\$ 350,000$; More than $\$ 350,000)$.

Social Mechanisms. In addition to the measures included in the multi-variate models, we also explore results from the final survey question, which asked: "One last question - when you were answering the last question and selected to give or donate your incentive, which of these best describes what you were thinking about in making your selection? Select all that apply. 1=I already give more than many others like me. $2=\mathrm{I}$ give about the same amount as others like me. $3=$ I give less than others like me. $4=$ Other people make a lot more money than my household. $5=$ Other people make about the same amount of money as my household. $6=$ Other people make a lot less money than my household. $7=\mathrm{I}$ really need the money. $8=\mathrm{I}$ do not really need the money. 9=Other people need the money." In the final set of models (Table 3), we include responses to this question in order to further examine potential social mechanisms. It is important to note that no respondents selected yes for the combination of responses of: 1-and-2, 1-and-3,2and-3, 4-and-5, 4-and-6, 5-and-6, 7-and-8, 7-and-9, or 8-and-9. Because these responses function as three subsets of responses based on: social norms (1-3), social needs (4-6), and social status (7-9), the first option in each subset is employed as the reference category for this analysis.

Analysis. Because our outcome is dichotomous (give vs. not give) and includes a number of covariates, we utilize multivariate logistic models regressing our giving outcome on binary treatment indicators (giving treatment, inequality treatment with our control group as the reference category), as well as the control covariates. As compared to other methods employed in 
experimental designs (e.g., ANCOVA), we focus on the overall direction and magnitude of our treatment variables controlling for other key characteristics associated with our giving outcome. For each model, we present the unstandardized coefficients representing change in the log odds for a one-unit increase in each covariate. Alternatively, each coefficient can be exponentiated to derive the odds ratios, with those greater than one indicating an increase in the odds of giving and those below one indicating a decrease in the odds of giving.

\section{Results}

\section{Giving Patterns}

We begin by first reviewing the descriptive statistics of the experimental results, displayed in Table 1, with an emphasis on the proportion of respondents (and their number) who chose to give versus those who did not. For ease of interpretation and because of the differences in our samples as previously discussed, we display the giving percentages separately for our treatment groups (control, giving, inequality, and both giving and inequality combined) and separately for our samples (Sample 1 and Sample 2) by treatment group.

\section{[Insert Table 1 About Here]}

We find, first, that the majority of participants across both studies elected to keep their incentives, rather than donate their incentives to a charitable organization: 14.50 percent donated their incentives $(n=29)$, while 85.50 percent kept their incentives $(n=171)$. Notably, respondents in both the giving and inequality treatment groups gave at a higher rate than in the control group overall and in each sample separately. However, the differences were not statistically significant at standard probability levels as shown in the second to last column of Table 1 (see the discussion for more information on this result). The only exception to this pattern was statistical 
significance found for the inequality treatment group giving 46.15 percent of the time as compared to 50.00 percent in the control group.

At the same time, however, we found statistically significant differences in giving across the two samples as displayed in the last column. Specifically, the proportion of respondents who gave was higher among the emerging adult, college sample overall (53.33 percent) as compared to the young adult, national sample (7.65 percent). Likewise, the proportion who chose to give after undergoing the giving treatment in the college sample (63.64 percent) was statistically significantly higher than the same treatment group in the national sample (8.20 percent).

Overall, across sample designs, social treatments result in greater giving on average than individual decision-making alone. However, the particular social mechanisms that operate on giving decisions appear to vary across samples. The college sample donated at a higher rate overall than the national sample. Moreover, the giving treatment elicited a greater donation rate for Sample 1 (compared to the control group and the inequality treatment), whereas the inequality treatment elicited a greater donation rate for Sample 2 (compared to the control group and the giving treatment). Counter to expectations, the inequality treatment stifled the donation rate for the college sample participants (compared to the control group). However, these results provide only an initial assessment of the study results, based on descriptive results alone.

\section{Predictors of Giving: Overall and College Sample Versus National Sample}

Building on the observed differences across our two samples, we turn now to examining the covariates of whether a respondent elected to give or not (dichotomous, $1=$ give). Model 1 presents models predicting giving as a function of treatment group along with controls for gender and income. Our primary finding is that, compared to the college sample of emerging adults, the 
likelihood of giving is lower in the national sample of young adults $(b=-2.286, p<.001)$. None of the other covariates are statistically significant.

\section{[Insert Table 2 About Here]}

Model 2 replicates Model 1 but is estimated separately for the college and national samples. We find that none of the covariates are statistically significant predictors of giving in the college sample as shown in Model 2a, whereas respondents with higher incomes are slightly more likely to give in the national sample as shown in Model $2 b(b=0.446, p<.10)$.

For Model 3, we add a control for whether a respondent was White versus non-White, which is not statistically significant. As with the previous set of models, respondents with higher incomes are more likely to give in the national sample as shown in Models $3 \mathrm{a}$ and $3 \mathrm{~b}(\mathrm{~b}=-0.017$, non-significant and $\mathrm{b}=0.463, \mathrm{p}<.05$, respectively). Taken as a whole, whether respondents chose to donate or not differed across samples, with some evidence that respondents with higher income were slightly more likely to give in the national sample of young adults.

Table 3 presents the results for Models 4-7. This set of models investigates the final question on the survey, which was asked after participants made their keep-or-give election. This question asked participants which explanation best described why they made their decision and included three sets of explanations. We categorize these as Giving Norms (amount of giving relative to others), Giving Needs (amount of need for self and others), and Giving Status (amount of money making relative to others). Returning to the simple model, we assess each set of these explanations independently and then together in a final model. Model 4 presents the results of logistic regression analyses of the giving behavior, with the treatment groups, and with the Giving Norms explanations. As discussed in the methods section above, the reference category for each subset of decision explanations is: "I already give more than many others like me." Both 
the other response options ("I give about the same as others like me." and "I give less than others like me.") are more likely to give than the reference category ( $b=1.042$ and 1.011, respectively). However, the results are not statistically significant.

\section{[Insert Table 3 About Here]}

Model 5 presents the results of a similar model, replacing Giving Needs for the norms included in the previous model. The results indicate that, compared to the self-need expressed in the reference category ("I really need the money."), both the other categories are associated with greater giving $(b=0.345$ for "I do not really need the money." and 0.755 "Other people need the money."). However, neither of these results is statistically significant.

Model 6 presents the results of a similar model, replacing needs with Giving Status explanations. Compared to the reference category ("Other people make a lot more money than my household.”), both of the other options are associated with greater giving. The third option (“Other people make a lot less money than my household.”) returns a beta of 0.719 . However, the result is not statistically significant. Alternatively, the second option ("Other people make about the same amount as my household.”) returns a statistically significant result of greater giving $(b=0.911, p<.01)$, net of treatment group in Model 6 . When entering all the giving explanations in the model together in Model 7, this result remains statistically significant $(b=$ $2.991, \mathrm{p}<.05)$.

It is worth noting that the lack of statistical significance in comparing giving across treatment groups in both study samples could be attributable to low levels of statistical power resulting from small sample sizes. Nevertheless, we assert that the general direction of the findings remains instructive, despite small sample sizes. Indeed, the differences in giving across treatments that we observe in this study would be statistically significant with modestly larger 
sample sizes: with power of 80 percent, simply doubling the sample size and keeping the proportions of giving across treatment and control groups would return statistically significant results. Thus, these findings provide initial evidence suggesting that: (a) giving remains a rare outcome regardless of exposure to any treatment effects, (b) exposure to social science research can impact giving, and (c) giving rates vary significantly across life course stages and by social statuses (e.g., college-enrolled students as compared to the general public). In summary, we find initial evidence that people respond to social science data in making charitable giving decisions.

\section{Discussion}

These data provide some initial results regarding the effect that different kinds of social science data have on individuals. In terms of our hypotheses, we find preliminary support for Hypothesis 1 - that individuals interacting with social norms data act prosocially at a higher rate than the control group. Thus, we find preliminary support for social - rather than purely individual-level - approaches to explaining actions. Stated differently, these results indicate that interacting with social science data about social norms of giving promotes greater giving.

However, the results are mixed with regard to the mechanisms that appear to operate in motivating social action. Namely, we find preliminary support for Hypothesis 1 and for Hypothesis 2, which were conceived of as alternative hypotheses. In general, participants interacting with charitable giving data donate at a higher rate than those interacting with weather data, and this finding is consistent across samples. While participants interacting with social stratification data also donate more than the control in Sample 2, participants in this treatment group in Sample 1 actually donate at a lower rate than either the control group participants, or the charitable giving participants. Yet, none of these factors are statistically significant predictors of 
giving in our logistic regression models. However, this is likely due to the small sub-sample sizes within each treatment group (see limitations section below for more information on this).

Returning to the theoretical frameworks, we find more direct support for a social norms mechanism than a social needs mechanism. It seems that individuals may be more compelled to give when informed of national and regional norms of giving among similar others than they are when informed of social inequalities. In essence, our findings indicate that individuals tend to give less out of compassion for those less fortunate or in light of pervasive inequities in our social system and more out of a sense of social desirability. Moreover, participating in social science research studying charitable giving may increase the rate at which people give, providing some support for the process of social research itself acting as an intervention of sorts in lifecourse generosity. The sole exception to this found here is that giving rates were higher for those who viewed other people as making about the same amount of money as their household. Though this does not entirely support a social needs theory, it indicates that equitable status may be a necessary pre-condition for electing to give one's incentive.

\section{Limitations}

Despite these contributions, there are important caveats that limit generalizability of these data. For one, the sample size limits the ability to perform inferential statistics to interpret the generalizability of these samples to the national population. This is not due to the size of the sample per se, but the rarity of the binary outcome relative to the sample sizes (Allison 2012; King \& Zeng 2001), especially within the national sample where the giving rate was low. We ran secondary analyses employing Firth logistical regression techniques to reduce the likelihood of small sample biases (not shown). In these models, the overall coefficient patterns of coefficient magnitude and direction of correlations remained stable, with minor increases in statistical power 
returned for all relationships. Thus, through a combination of the statistical fact that greater sample size increases statistical power and the results of this additional models, we think that these initial findings underscore the importance of continuing this investigation within a larger and nationally representative survey sample.

Additionally, it is worth noting that there could be more self-selection or socialdesirability effects embedded in the college sample, since responses were collected only from students who responded to an announcement about the study, and the students may have donated more because they were concerned about their reputation on campus (compared to the greater anonymity of the sample in Sample 2). Yet, we employed measures to lessen this possibility, such as posting this announcement to a campus-wide news forum and seeking distribution assistance from a variety of sources on campus in order to limit any systematic bias in who responded. However, it remains possible that Sample 1 was influenced by the context of the study in ways that the participants in Sample 2 were not, perhaps accounting for some or all of their greater propensity to donate. If this was the case, other samples employing college-selected emerging adults may also be affected by these same over-donating potentials. Thus, this potential limitation further underscores the need to collect data from relatively large nationally representative and randomly selected samples.

Nevertheless, it is important to note that the income levels vary between the two samples, with the college-student sample living within a median household income level of $\$ 100,001$ 150,000 , as compared to the national sample having a median household income level of $\$ 50,0001-\$ 100,000$. Though income level is not statistically significant in Model 1 and Model 2, it is possible that the difference in income levels overall between the two samples could account for their higher giving rate overall, even while within this model differing income levels are not 
statistically significant in predicting variability in giving rates within the college-student sample. To further investigate this possibility, we ran interaction models with income but these models (not shown) did not yield statistically significant results. However, it is again possible that the rare event and associated small number of cases could be responsible for this lack of statistical significance. Thus, the comparison between samples needs to be interpreted cautiously. More generally, these results underscore the need to not rely on college samples alone, since national samples can provide greater income diversity.

Finally, the behavioral outcome measure employed in this study is an "all-or-nothing" design. Participants only have the dichotomous options to give away all of their incentive or keep all of their incentive. An alternative approach would be to ask respondents to elect what portion of their incentive they want to give. Nothing would still be an option, but so would variable amounts of giving between $\$ 1$ and the full amount of $\$ 50$. If more respondents gave with the option to give in smaller amounts, then greater statistical power could result from this alternative study design. However, that design would then focus on the economics of greater and lower amounts of giving, whereas the dichotomous outcome of this survey focuses instead on the overall rate of prosocial behavior. From an economic perspective alone, attention to variable amounts of donation election may be more ideal. However, from our sociological perspective, we are more interested in net gains to rates of participation in prosocial behavior. Nevertheless, future studies could design variable amounts of incentives donated to focus attention on economic outputs of social science interactions. This could also yield greater statistical power by reducing the rare binary outcome, but alternatively the focus on binary prosocial rates would be supported by a larger sample with greater number of donator cases. 


\section{Implications \& Future Studies}

Despite these limitations in generalizability, this study provides initial evidence regarding the potential for websites presenting interactive social science data to impact giving decisions and thereby potentially increase the rate of prosocial behaviors. The major implication is that well-constructed visualizations of social science data can contribute to greater charitable giving. We also found initial support for a social norms mechanism, more so than a social needs mechanism, as the way that interacting with social science data can compel charitable giving. Within the context of this study, the social needs mechanism does not appear to promote giving as strongly, and in some cases may actually inhibit giving.

Methodological Implications. Future studies should investigate these results further to conceptualize other ways of invoking a social needs mechanism and measuring its impact on giving. There is also the possibility that the social inequality treatment may provoke other responses than charitable giving. For example, people may elect to politically engage or volunteer at a greater rate in response to data about social inequality. This is also an important possibility to investigate in future studies, and these preliminary data indicate that future studies on these issues are warranted. Lastly, the study supports the need to collect data with national samples, rather than with college students alone, given the considerably higher average income level and (perhaps associated) higher donation rate among college students, as compared to national participants. Indeed, college students' incomes are often confounded by varying degrees of dependency on parental resources that are not disentangled from questions asking about students' own income. Additionally, future studies should track national samples of participants longitudinally as a way to disentangle age and life stage in comparisons across samples. The 
exploratory results here regarding giving decision explanations (Table 3) indicate that future studies should ask these questions as three discrete questions, each with forced-response options.

Practical Implications. In terms of practical implications that could be derived from this study, we offer two primary implications for fundraising practices. First, this study can be interpreted as indicating that presenting potential donors with social science data prior to asking for donations can be an effective tool. In particular, it appears that showing potential donors visuals of data regarding the giving behavior of others can invoke a social norms response mechanism that promotes giving. Moreover, the findings in this study can also be interpreted to indicate that social norms data is effective when potential donors are shown segmented data, meaning the data about giving are matched to the donors' social identity reference groups, thereby potentially inhibiting a tendency to assume that general social norms do not apply. Second, this study indicates that invoking social needs responses may not be an effective fundraising strategy, or at least that fundraisers need to better understand how a redistributive justice response could be effective in invoking giving. Our study indicates that the social needs mechanism needs additional attention, especially with studies focusing on national samples.

Scholarly Implications. In addition to these practical implications, there are two primary theoretical implications that can be derived from this study. First, a Durkheimian approach to charitable giving receives the most consistent empirical support in this study. Social norms mechanisms appear to be operative in giving decision-making. More generally, this highlights important social dynamics embedded in what can otherwise be construed as an individualistic, ego-based, economic action: charitable giving. Second, rather than dismiss the potential theoretical contributions of a Weberian approach, this empirical test indicates that greater attention is needed to the role of social inequality in giving behavior. The greater average 
household income level of college students may be related to their higher giving rate, which means that experimental studies focusing on college-based samples may be overrepresenting the propensity to give, and thus results regarding what influences giving may also be overstated. Moreover, there may be important interaction effects between income level and treatment groups, as is initially indicated by the statistical significance of income in the national sample. Thus, relatively large national samples are needed to further investigate the complex inequalitygiving dynamics.

Additionally, this study indicates that social inequality may invoke a competitive reaction, rather than a redistributive value-based response. For example, Blau (2017) finds that economic imbalances in power, prestige, and social status are often legitimized through reified group structures. In other words, showing potential donors visuals about social inequality may provoke a defensive mechanism that causes people to justify clinging to greater resources, rather than priming readiness to redistribute resources. In this case, finding that the social inequality treatment is either non-effective, or actually lowers the propensity to give, is ultimately still potentially confirming of Weberian theories regarding the importance of social status and valuebased actions. However, the hypothesis may need to be inverted in response to this study, expecting that social inequality data may reinforce self-focused values and competitive actions, rather than redistributive values and prosocial actions.

\section{Conclusion}

In conclusion, this study provides initial evidence regarding the influence of visualized social science data in affecting giving behavior. Social norms mechanisms appear to be most effective in promoting greater prosocial action. Alternatively, visualized social inequality data may actually decrease the propensity to act prosocially, at least for some social groups. This 
study makes a number of practical and scholarly contributions, including informing the use of social science data in fundraising practices. At the same time, the limited generalizability of these results requires caution in interpreting implications and warrants further investigation.

\section{References}

Abrams, Dominic, and Michael A. Hogg. 1998. Social Identification: A Social Psychology of Intergroup Relations and Group Processes. London: Routledge.

Addams, Jane. 1999. Twenty Years at Hull-House, Reprint edition. Westminster, UK: Signet. Arnett, Jeffrey. 2015. Emerging Adulthood: The Winding Road form the Late Teens Through the Twenties. New York: Oxford University Press.

Bandura, Albert. 1989. "Human Agency in Social Cognitive Theory.” American Psychologist, 44(9): 1175-1184.

Bekkers, René, and Pamala Wiepking. 2010. “Accuracy of Self-Reports on Donations to Charitable Organizations. ” Quality \& Quantity, 45(6): 1369-1383.

-----. 2011. “A Literature Review of Empirical Studies of Philanthropy.” Nonprofit and Voluntary Sector Quarterly, 40(5): 924-973.

Benz, Matthias, and Stephan Meier, 2008. "Do People Behave in Experiments as in the Field? Evidence from Donations.” Experimental Economics, 11: 268-281.

Blau, Judith R. and Peter M. Blau. 1982. "The Cost of Inequality: Metropolitan Structure and Violent Crime.” American Sociological Review, 47(1): 114-129.

Blau, Peter M. 2017. Exchange and Power in Social Life, $2^{\text {nd }}$ edition. New York: Routledge. Carpenter, Jeffrey P., Stephan Burks, and Eric Verhoogen. 2005. “Comparing Students to Workers: The Effects of Social Framing on Behavior in Distribution Games.” In Glenn 
W. Harrison, Jeffrey Carpenter, and John A. List (Eds.), Field Experiments in Economics, Research in Experimental Economics, vol. 10. Amsterdam: JAI Press, pp. 261-289.

Carpenter, Jeffrey P., Christina Connolly, and Caitlin K. Myers. 2008. “Altruistic Behavior in a Representative Dictator Experiment.” Experimental Economics, 11: 282-298.

Christensen, P. Niels, Hank Rothgerber, Wendy Wood, and David C. Matz. 2004. "Social Norms and Identity Relevance: A Motivational Approach to Normative Behavior." Personality and Social Psychology Bulletin, 30(10):1295-1309.

Côté, Stéphane, Julian House, and Robb Willer. 2015. "High Economic Inequality Leads HigherIncome Individuals to Be Less Generous." Proceedings of the National Academy of Sciences of the United States of America (PNAS), 112(52): 15838-15843.

de Oliveira, Angela C.M., Rachel T.A. Croson, and Catherine Eckel. 2011. "The Giving Type: Identifying Donors." Journal of Public Economics 95 428-435.

Deegan, Mary J. 1988. Jane Addams and the Men of the Chicago School, 1892-1918. Transaction Publishers.

DellaVigna, Stefano, John A. List, and Ulrike Malmendier. 2012. "Testing for Altruism and Social Pressure in Charitable Giving." The Quarterly Journal of Economics, 127(1): 156.

Derin-Gure, Pinar and Neslihan Uler. 2010. "Charitable Giving Under Inequality Aversion." Economics Letters, 107(2): 208-210.

Durkheim, Émile. 1984. The Division of Labor in Society. New York: The Free Press. First published in 1893.

Durkheim, Émile. 1982. The Rules of Sociological Method. (Steven Lukes, editor and W. D. Halls, translator). New York: The Free Press. First published in 1919. 
Eckel, Catherine C., and Philip J. Grossman. 1996. "Altruism in Anonymous Dictator Games.” Games and Economic Behavior, 16: 181-191.

Elder, Glen H. 1994. “Time, Human Agency, and Social Change: Perspectives on the Life Course." Social Psychology Quarterly, 57(1): 4-15.

Frey, Bruno S. and Stephan Meier. 2004. "Social Comparisons and Prosocial Behavior: Testing 'Conditional Cooperation' in a Field Experiment.” The American Economic Review, 94(5): 1717-1722.

Hochschild, Jennifer L. 1981. What's Fair? American Beliefs about Distributive Justice. Cambridge, MA: Harvard University Press.

Hogg, Michael A. and Scott A. Reid. 2006. "Social Identity, Self-Categorization, and the Communication of Group Norms.” Communication Theory, 16(1): 7-30.

Laury, Susan K., and Laura O. Taylor. 2008. “Altruism Spillovers: Are Behaviors in ContextFree Experiments Predictive of Altruism Toward a Naturally Occurring Public Good?" Journal of Economic Behavior and Organization, 65: 9-29.

McAuliffe, Katherine, Nichola J. Raihani, and Yarrow Dunham. 2017. "Children are Sensitive to Norms of Giving.” Cognition, 167: 151-159.

Paluck, Elizabeth Levy, and Hana Shepherd. 2012. "The Salience of Social Referents: A Field Experiment on Collective Norms and Harassment Behavior in a School Social Network." Journal of Personality and Social Psychology, 103(6):899-915.

Pescosolido, Bernice A. 1992. "Beyond Rational Choice: The Social Dynamics of How People Seek Help.” American Journal of Sociology, 97(4): 1096-1138.

Porterfield S. L. \& Winkler, A. E. 2007. "Teen time use and parental education: Evidence from the CPS, MTF, and ATUS.” Monthly Labor Review, 130(5):37-56. 
Putnam, Robert D., Carl B. Frederick, and Kaisa Snellman. 2012. “Growing Class Gaps in Connectedness among American Youth, 1975-2009.” Harvard Kennedy School of Government, The Saguaro Seminar: Civic Engagement in America. Retrieved from: http://www.hks.harvard.edu/var/ezp_site/storage/fckeditor/file/SaguaroReport_Diverging SocialConnectedness_20120808.pdf

Raihani, Nichola J., and Katherine McAuliffe. 2014. "Dictator Game Giving: The Importance of Descriptive versus Injunctive Norms.” PLoS One, 9(12): 1-17.

Rochat, Phililppe, Maria D. G. Dias, Guo Liping, Tanya Broesch, Claudia Passos-Ferreira, Ashley Winning, and Britt Berg. 2009. "Fairness in Distributive Justice by 3- and 5-YearOlds Across Seven Cultures.” Journal of Cross-Cultural Psychology, 40: 416-442.

Rose, Stephen J. 2015. Social Stratification in the United States; The American Profile Poster. $4^{\text {th }}$ ed. New York: The New Press.

Scott, John. 2000. "Rational Choice Theory.” In Gary Browning, Abigail Halcli, and Frank Webster (eds.), Understanding Contemporary Society: Theories of the Present. Thousand Oaks, CA: SAGE Publications Inc. pp. 126-138.

Turner, Stephan P. and Jonathan H. Turner. 1990. The Impossible Science: An Institutional Analysis of American Sociology. Thousand Oaks, CA: Sage Publications.

Vaughan, Ted R., Gideon Sjoberg, Larry T. Reynolds. 1993. A Critique of Contemporary American Sociology. Lanham, MA: Rowman \& Littlefield.

Vesterlund, Lise. 2016. "Using Experimental Methods to Understand Why and How we Give to Charity.” In John H. Kagel and Alvin E. Roth (Eds.), Handbook of Experimental Economics, 2 ed. Princeton, NJ: Princeton University Press. Pp. 91-151. 
Weber, Max 1946. From Max Weber: Essays in Sociology. New York: Oxford University Press. First published in 1904.

Weber, Max. 1949. The Methodology of the Social Sciences. New York: Free Press. First published in 1913-1917.

Wilhelm, M. O. 2016. "The Quality and Comparability of Survey Data on Charitable Giving." Nonprofit and Voluntary Sector Quarterly, 36(1): 65-84.

Zou, Xi, Kim-Pong Tam, Michael W. Morris, Sau-Lai Lee, and Ivy Yee-Man Lau. 2009. "Culture as Common Sense: Perceived Consensus versus Personal Beliefs as Mechanisms of Cultural Influence." Journal of Personality and Social Psychology, 97(4):579-97. 
Figure 1. GenerosityForLife Website for Charitable Giving Treatment Group Interaction Answer 5 Quick Questions....

What is your age?
$\underset{16-29}{\mathrm{O}}$
$30-39$
$\underset{40-49}{\mathrm{C}_{4}}$
${ }_{50-59}$
$\underset{60-69}{\mathrm{O}}$
$\mathrm{O}_{70+}$

What is the highest education level you attained?

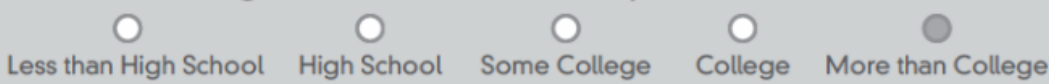

Where do you live?

Michigan

Estimate how much money you donated last year:

$\begin{array}{cccccc} & \bigcirc & \bigcirc & \bigcirc & \bigcirc & \bigcirc \\ \text { None } & \$ 1-\$ 100 & \$ 101-\$ 1,000 & \$ 1,001-\$ 5,000 & \$ 5,001-\$ 10,000 & \$ 10,001+\end{array}$

Estimate how much time you donated last year:

$\begin{array}{cccccc}\text { None } & 1-50 & 51-100 & 101-500 & 501-1,000 & 1,001+ \\ & \text { hours } & \text { hours } & \text { hours } & \text { hours } & \text { hours }\end{array}$

Giving patterns for individuals in your region with similar demographics to you.

\section{Midwest Region}

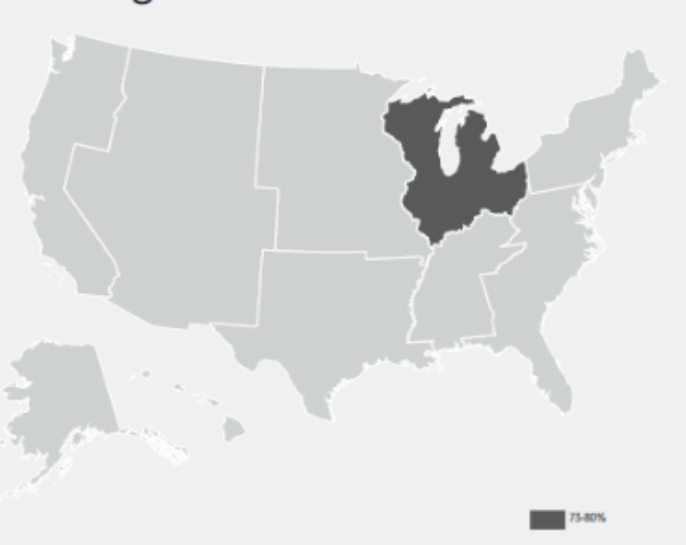

How do you compare?
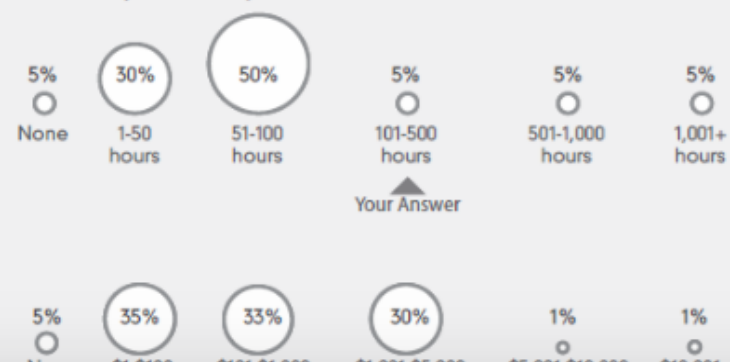

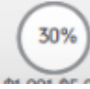

$1 \%$

$1 \%$
On average, they give

$\$ 1,200$

Gave money to charities

volunteered their time

They gave to the following types of organizations:

to charity annually.

$\$ 800$

is the median
$65 \%$ Arts + Culture

$35 \%$ Basic Needs

$85 \%$ Education

$55 \%$ Environment + Animals

$90 \%$ Health

$65 \%$ International

$35 \%$ Neighborhood + Community

$85 \%$ Youth + Family

$55 \%$ Religious

$90 \%$ Secular

Metadata? Methodology? Data Sources? 
Figure 2. Social Stratification in the U.S. Poster for Inequality Treatment Group

[See article in print due to copyright permission restrictions.] 


\begin{tabular}{|c|c|c|c|c|c|c|}
\hline Participant Characteristics & $\begin{array}{c}\text { Give } \\
\mathbf{N}\end{array}$ & $\begin{array}{c}\text { Give } \\
\%\end{array}$ & $\begin{array}{c}\text { Keep } \\
\mathbf{N}\end{array}$ & $\begin{array}{c}\text { Keep } \\
\%\end{array}$ & $\begin{array}{c}\text { Treatment } \\
\text { vs. } \\
\text { Control }\end{array}$ & S1 vs. $\mathbf{S 2}$ \\
\hline Overall Giving Rate: Combined Samples & 29 & $14.50 \%$ & 171 & $85.50 \%$ & - & - \\
\hline \multicolumn{7}{|l|}{ Giving by Group } \\
\hline Control Group & 6 & $10.17 \%$ & 53 & $89.83 \%$ & - & - \\
\hline Giving Treatment & 12 & $16.67 \%$ & 60 & $83.33 \%$ & NS & - \\
\hline Inequality Treatment & 11 & $15.94 \%$ & 58 & $84.06 \%$ & NS & - \\
\hline Treatment Groups Combined & 23 & $16.31 \%$ & 118 & $83.69 \%$ & NS & - \\
\hline \multicolumn{7}{|l|}{ Giving by Sample and Group } \\
\hline Sample 1: Emerging-Adult, College Sample & 16 & $53.33 \%$ & 14 & $45.16 \%$ & - & * \\
\hline Control Group & 3 & $50.00 \%$ & 3 & $50.00 \%$ & - & NS \\
\hline Giving Treatment & 7 & $63.64 \%$ & 4 & $36.36 \%$ & NS & $*$ \\
\hline Inequality Treatment & 6 & $46.15 \%$ & 7 & $53.85 \%$ & NS & NS \\
\hline Sample 2: Young-Adult, National Sample & 13 & $7.65 \%$ & 157 & $92.35 \%$ & - & $*$ \\
\hline Control Group & 3 & $5.66 \%$ & 50 & $94.34 \%$ & - & NS \\
\hline Giving Treatment & 5 & $8.20 \%$ & 56 & $91.80 \%$ & NS & $*$ \\
\hline Inequality Treatment & 5 & $8.93 \%$ & 51 & $91.07 \%$ & NS & NS \\
\hline
\end{tabular}

Source: Author calculations (ELS 2017).

Notes: $\mathrm{NS}=$ non-significant, ${ }^{*} \mathrm{p}<.05,{ }^{* *} \mathrm{p}<.01,{ }^{* * *} \mathrm{p}<.001$ relative to the results of $\mathrm{t}$-tests for differences in proportions. S1 and S2 in the far-right column = Sample 1 and Sample 2; statistical significance here refers to results of tests comparing differences in proportions across the two different samples. 
Table 2. Logistic Regression Results for Giving Behavior by Treatment Group: Overall and College Sample Vs. National Sample

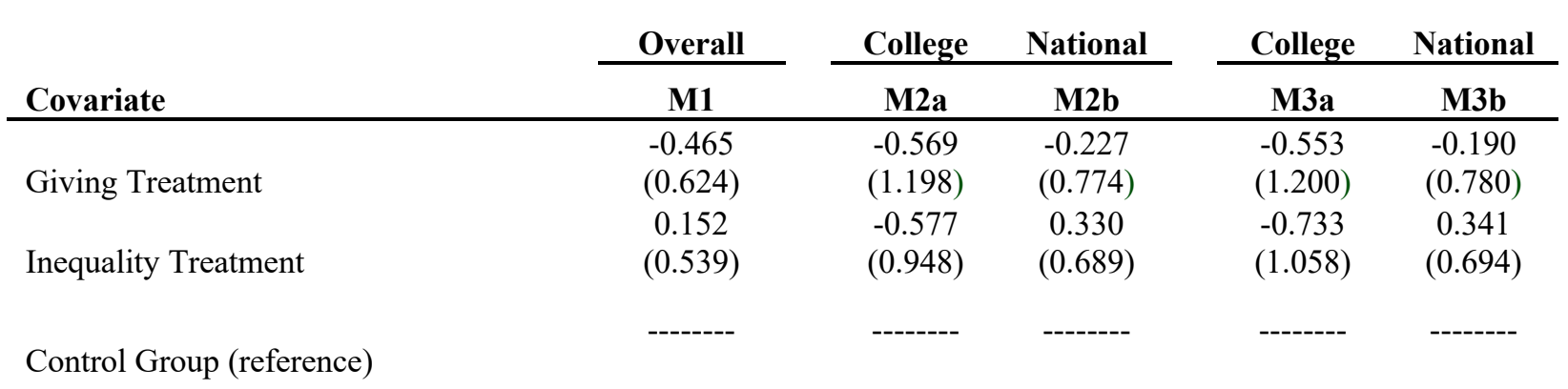

\section{Control Measures}

Gender

\begin{tabular}{|c|c|c|c|c|c|}
\hline Female & $\begin{array}{c}0.587 \\
(0.513)\end{array}$ & $\begin{array}{l}-0.465 \\
(0.624)\end{array}$ & $\begin{array}{c}0.301 \\
(0.608)\end{array}$ & $\begin{array}{c}1.362 \\
(0.973)\end{array}$ & $\begin{array}{c}0.309 \\
(0.611)\end{array}$ \\
\hline \multicolumn{6}{|l|}{ Male (reference) } \\
\hline \multicolumn{6}{|l|}{ Race and Ethnicity } \\
\hline White or Caucasian & -------- & -------- & -------- & $\begin{array}{l}-0.403 \\
(1.146)\end{array}$ & $\begin{array}{l}-0.462 \\
(0.647)\end{array}$ \\
\hline Multiracial or Other Race (reference) & 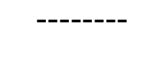 & - & ------ & -------- & ----. \\
\hline Household Income (6 categories) & $\begin{array}{c}0.236 \\
(0.1830\end{array}$ & $\begin{array}{c}-0.049 \\
(0.317)\end{array}$ & $\begin{array}{l}0.446 \dagger \\
(0.234)\end{array}$ & $\begin{array}{c}-0.017 \\
(0.332)\end{array}$ & $\begin{array}{l}0.463 * \\
(0.235)\end{array}$ \\
\hline $\begin{array}{l}\text { Sample Type } \\
\text { Sample 1: Emerging, College (reference) }\end{array}$ & -------- & -------- & -------- & -------- & -------- \\
\hline Sample 2: Young-Adult, National & $\begin{array}{c}-2.286^{* * *} \\
(0.496) \\
\end{array}$ & -------- & ------- & -------- & -------- \\
\hline Constant & $\begin{array}{r}1.429 \\
(1.079)\end{array}$ & $\begin{array}{c}-.595 \\
(1.081)\end{array}$ & $\begin{array}{l}-.595 \\
(1.081)\end{array}$ & $\begin{array}{l}-0.278 \\
(1.405)\end{array}$ & $\begin{array}{l}-3.381 \\
(0.962) \\
\end{array}$ \\
\hline
\end{tabular}

Source: Author calculations (ELS 2017).

Note: $\dagger \mathrm{p}<.10,{ }^{*} \mathrm{p}<.05,{ }^{* *} \mathrm{p}<.01,{ }^{*} \mathrm{p}<.05$ 
Table 3. Logistic Regression Results for Giving and Social Mechanism Explanations For National Sample

\begin{tabular}{lcccc}
\hline Covariate & M4 & M5 & M6 & M7 \\
\hline & -0.435 & -0.521 & -0.755 & -0.978 \\
Giving Treatment & $(0.763)$ & $(0.772)$ & $(0.815)$ & $(0.848)$ \\
& 0.101 & -0.019 & -0.171 & -0.313 \\
Inequality Treatment & $(0.880)$ & $(0.977)$ & $(0.696)$ & $(0.718)$ \\
Control Group (reference) & ------- & ------- & ------ & -------
\end{tabular}

\section{Social Mechanisms}

\section{Giving Norms}

I already give more than many others like me. (reference)

1.042

(667)

I give less than others like me.
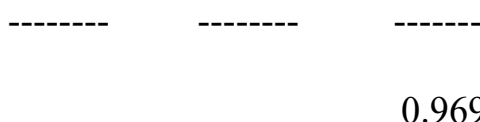

0.969

$(0.918)$

0.516

$(0.941)$

\section{Giving Needs}

I really need the money. (reference)

I do not really need the money.

$0.345 \quad-1.720$

(1.112)

(1.164)

0.755

1.026

Other people need the money.

$(0.721)$

$(0.793)$

\section{Giving Status}

Other people make a lot more money than my household. (reference)

Other people make about the same amount as my household.

Other people make a lot less money than my household.

\begin{tabular}{|c|c|c|c|}
\hline & & $\begin{array}{c}2.911 * * \\
(1.108)\end{array}$ & $\begin{array}{l}2.991^{*} \\
(1.174)\end{array}$ \\
\hline ----- & -- & $\begin{array}{c}0.719 \\
(0.522)\end{array}$ & $\begin{array}{c}0.302 \\
(1.200)\end{array}$ \\
\hline $\begin{array}{c}-2.630^{* * *} \\
(0.504)\end{array}$ & $\begin{array}{c}2.516^{* *} \\
(0.485) \\
\end{array}$ & $\begin{array}{c}-2.447 * * * \\
(0.471)\end{array}$ & $\begin{array}{c}-2.721 * * * \\
(0.518) \\
\end{array}$ \\
\hline
\end{tabular}

Constant

Source: Author calculations (ELS 2017).

Note: $\dagger \mathrm{p}<.10,{ }^{*} \mathrm{p}<.05,{ }^{* *} \mathrm{p}<.01,{ }^{*} \mathrm{p}<.05$ 